KS. ANDRZEJ ZIAREK* - LUBLIN

\title{
LA ELABORACIÓN Y LA ESTRUCTURA DEL CATECISMO ROMANO
}

\section{La elaboración y la edición típica del Catecismo Romano}

Ya los padres del Concilio de Tortosa de 1429 señalaron la necesidad de elaborar un catecismo universal para toda la Iglesia Católica ${ }^{1}$. Porque hasta la mitad del siglo XVI no existían en la historia catecismos que salieran de la iniciativa papal o conciliar y tuvieran un carácter normativo para la Iglesia universal. Hasta ahora, todas las obras catequéticas fueron, en cierto sentido, iniciativas particulares. Alguien - un teólogo, un pastor o un laico, escribía su obra como una ayuda, como un subsidium y la ofrecía a la Iglesia para que ésta enseñara a través de ella al pueblo y para que al mismo tiempo éste la aprenda ${ }^{2}$.

La situación cambió en el siglo XVI bajo la influencia de varios factores. Ante todo, la ruptura de la fe, que provocó Lutero y sus seguidores, obligó en cierto modo a la Iglesia Católica a definir su doctrina ${ }^{3}$. A su vez esto provocó la necesidad de convocar un concilio. Cada concilio era una reunión del clero de todos los niveles y de varios teólogos y daba la oportunidad de intercambiar ideas. También durante el concilio se elaboraron documentos, que luego, en la mayoría de los casos, se dieron a conocer a toda la Iglesia. Así pues, existía la oportunidad para crear un catecismo universal. El otro factor que influyó en la elaboración de éste fue la necesidad de salir al paso de la ignorancia de los fieles, que muchas veces vivían en un ambiente cristiano, pero con escaso conocimiento y fundamentación personales del mensaje vivo del Evangelio ${ }^{4}$. También los sacerdotes responsables

* Ks. Andrzej Ziarek - doktorando en la Universidad Cathólica de Lublin/ mgr lic. teologii, doktorant w Instytucie Historii i Patrologii KUL, e-mail: andrzej.ziarek@gmail.pl

${ }^{1}$ Cf. L. Resines, La catequesis en España. Historia y textos, Madrid 1997, pp. 53-55; y también A. Etchegaray-Cruz, Storia della catechesi, Roma 1984, p. 200.

${ }^{2}$ Cf. J. M. E. Llaurens, P. Rodríguez García, J. A. Gallego, Estudios sobre el Catecismo de la Iglesia Católica, Madrid 1996, p. 3.

${ }^{3}$ Cf. B. Kumor, Historia Kościoła, vol. 5, Czasy nowożytne, rozłam w chrześcijaństwie zachodnim, Lublin 1984, pp. 161-166.

${ }^{4}$ Cf. J. M. E. Llaurens, P. Rodríguez García, J. A. Gallego, Estudios sobre el Catecismo de la Iglesia Católica, Madrid 1996, p. 2. 
de la formación espiritual de los fieles, pidieron este tipo de manual. Así que, todos estos factores interiores y exteriores dieron lugar a una inimitable ocasión para crear el primer catecismo universal de la Iglesia Católica ${ }^{5}$.

Por primera vez, la cuestión del nuevo catecismo universal fue presentada en el Concilio de Trento en la congregación general el día 5 de abril de $1546^{6}$. Los padres conciliares postularon para que el futuro catecismo se elaborara desde el punto de vista de la preparación de los fieles a la lectura de la Sagrada Escritura. Se trataba de que los fieles entendieran la Biblia según la doctrina oficial de la Iglesia Católica. Este postulado fue planteado, porque en algunos lugares se abusaba de la Sagrada Escritura ante todo, bajo la influencia de la doctrina protestante ${ }^{7}$. También es necesario destacar aquí, que el Concilio, revisando la catequesis pretridentina, restableció la Sagrada Escritura en el primer puesto de toda la enseñanza católica. Pues, en la concepción del Concilio, la Palabra Divina tenía que convertirse en un elemento principal de la catequesis ${ }^{8}$. A su vez, ésto significó la vuelta a las fuentes: a la Sagrada Escritura, a los Padres de la Iglesia y a las mejores obras escolásticas. Todos estos postulados tuvieron una gran influencia en la forma del nuevo catecismo?.

En la siguiente congregación, el día 13 de abril de 1546, se presentó a los padres conciliares el proyecto sobre la elaboración del nuevo catecismo. Este proyecto instauró que el futuro catecismo fuese la obra del Concilio, apoyada por citas de la Sagrada Escritura y de los Padres de la Iglesia, editada en lengua latina y en lenguas nacionales y dirigida a la enseñanza de los niños y de la gente inculta $^{10}$. También se decidió que el nuevo catecismo sólo contuviese la confesión positiva de la fe, es decir, no entrase en la polémica con los protestantes ${ }^{11}$.

Cuando el Concilio se trasladó a Bolonia en la congregación general del 14 de octubre de 1547 una vez más volvió la cuestión del nuevo catecismo. Cuatro días después se formó una comisión especial, cuya tarea fue elaborar un esquema. A esta comisión pertenecieron: Benedetto di Nobilis el obispo de Accia en Córce-

${ }^{5}$ Cf. P. Rodríguez, R. Lanzetti, El Catecismo Romano: fuentes e historia del texto y de la redacción. Bases críticas para el estudio teológico del Catecismo del Concilio de Trento 1566, Pamplona 1982, p. 19. Citado más adelante como: P. Rodríguez, R. Lanzetti, El Catecismo Romano: fuentes e historia del texto y de la redacción.

${ }^{6}$ El texto de esa propuesta presentada por Cornelio Musso en la congregación general se puede leer en P. Rodríguez, R. Lanzetti, El Catecismo Romano: fuentes e historia del texto y de la redacción. Pamplona 1982, pp. 30-32.

${ }^{7}$ Cf. J. Z. Słowiński, Katechizmy katolickie w języku polskim od XVI do XVIII wieku, Lublin 2005 , p. 87.

${ }^{8}$ Cf. A. Etchegaray-Cruz, Storia della catechesi, Roma 1984, pp. 202-203.

${ }^{9}$ Cf. A. Alberigo, Nowe poglądy na Sobór Trydencki, „Concilium”, 1-2 (1965-1966) p. 540.

10 "Pro pueris autem et adultis indoctis erudiendis, quibus lacte opus est, non solido cibo, curet sancta synodus a viris doctis et piis in lingua latina et vulgari edi catechismum ex ipsa sacra scritura et patribus orthodoxis excerptum, ut illius paedagogia instituti a magistris suis et memores sint Christianae professionis, quam fecerunt in baptismo, et praeparentur ad studia sacrarum litterarum." citado por P. Rodríguez, R. Lanzetti, El Catecismo Romano, p. 32; y también M. Popielec, Katechizm kaliski i jego znaczenie dla polskich edycji Katechizmu Rzymskiego, Lublin 1970, p. 16.

${ }^{11}$ Cf. P. Paschini, Cinquecento romano e riforma cattolica, Roma 1958, p. 36. 
ga, Roberto Cenan el obispo de Avranches en Francia, Egidio Falcetta el obispo de Caorle, Cornelio Musso el obispo de Bitonto, Gian Pietro Feretto el obispo de Milo y Alvise Lippomano el obispo de Verona ${ }^{12}$. Pero no se hizo nada más porque en el año 1548 el Concilio quedó suspendido.

En enero de 1562 el Concilio al renovarse los debates en Trento, apareció de nuevo la idea del catecismo, junto con el tema del Index. Así, pues, surgió la propuesta para que todos los catecismos erróneos y sospechosos fueran excluidos del uso y fueran puestos en el Index. De este modo se quería elaborar un sólo catecismo, que fuera válido para toda la Iglesia Católica ${ }^{13}$. Por la misma línea seguían los postulados del emperador Fernando I de Austria. Presentada por sus delegados la obra El libro sobre la reforma, preparada por una comisión especial, contenía la propuesta de elaborar un compendio de la fe católica. Esta obra tenía que contener sólo las cuestiones negadas por los protestantes. Los delegados presionaron a los padres conciliares para que éstos aprobaran la elaboración de este compendio y lo presentaran como obligatorio en todas las provincias eclesiales. Según la idea de los austríacos, el manual, anotado por la autoridad del Concilio y los gobernantes, tenía que servir a los párrocos en la enseñanza del pueblo ${ }^{14}$. Así, pues, el futuro catecismo tenía que ser ante todo un instrumento en la lucha política y religiosa con los heterodoxos ${ }^{15}$. El mismo cargo ocuparon los obispos franceses y el día 3 de enero de 1563 lo presentaron al Concilio. En cambio Pedro Canisio salió con otra propuesta. Se dirigió al cardenal polaco Estanislao Hossio, que en este tiempo presidía los debates, para que el Concilio confirmara la ortodoxia de su propio Catecismo Mayor y lo reconociera como válido para toda la Iglesia ${ }^{16}$. Incluso el representante del emperador Fernando I, Anton Bruz de Muglitz, el obispo de Praga, introdujo el texto del catecismo de Canisio en los debates conciliares. Canisio en la carta del 16 de marzo de 1562 dirigida al cardenal Hossio escribió que no estaba en contra de que el Concilio edite un catecismo mejor que el suyo ${ }^{17}$. Una de las comisiones advirtió que para la elaboración del nuevo catecismo se puede aprovechar Opus catecheticum de Canisio, que en este tiempo gozaba de gran éxito. El rey de Francia compartió la misma opinión. La popularidad que tenían los catecismos de Canisio surgía del hecho de que gran parte ocuparon en esas obras las cuestiones discutibles con los protestantes ${ }^{18}$. Sin embargo, al final,

${ }^{12}$ Cf. P. Rodríguez, R. Lanzetti, El Catecismo Romano, pp. 39-43.

${ }^{13}$ Cf. P. Paschini, Cinquecento romano e riforma cattolica, Roma 1958, p. 40.

${ }^{14}$ Ibídem, pp. 41-42; y también H. Jedin, Geschichte des Konzils von Trient, Bd. 4: Dritte Tagunsperiode und Abschluss, Hlbd. 1: Frankreich und der neue Anfang in trient bis zum Tode der Legaten Gonzaga und Seripando, Freiburg 1975, p. 101.

${ }^{15}$ Cf. H. Jedin, Geschichte des Konzils von Trient, Bd. 4: Dritte Tagunsperiode und Abschluss, Hlbd. 2: Überwindung der Krise durch Morone, Schliessung und Bestätigung, Freiburg 1975, p. 237; y también P. Paschini, Cinquecento romano, pp. 42-43.

${ }^{16}$ Cf. P. Rodríguez, R. Lanzetti, El Catecismo Romano, pp. 49-50.

${ }^{17} \mathrm{Cf}$. H. Jedin, Geschichte des Konzils von Trient, Bd. 4: Dritte Tagunsperiode und Abschluss, Hlbd. 2: Überwindung der Krise durch Morone, Schliessung und Bestätigung, p. 304.

${ }^{18}$ Cf. J. Z. Słowiński, Katechizmy katolickie w języku polskim od XVI do XVIII wieku, Lublin 2005, p. 89; y también A. Etchegaray-Cruz, Storia della catechesi, Roma 1984, p. 221. 
los padres conciliares no aceptaron esta propuesta y los catecismos de Canisio no fueron usados.

El día 5 de marzo de 1563 se tomó la decisión para distinguir de la Comisión del Index algunos padres y construir con ellos un grupo pro Catechismo ${ }^{19}$. La iniciativa salió de la misma Comisión del Index, la cual en la reunión del 27 de abril de 1563 afirmó que casi todos los catecismos que fueron elaborados hasta ahora se hallaron en el Index del papa Pablo III $^{20}$. La nueva Comisión establecida dividió entre los padres conciliares el material, que se tenía que hallar en el futuro catecismo. El Símbolo de la fe tenían que prepararlo tres teólogos españoles, como "más seguros en la fe", Santotis, Madina y Fuentidueña ${ }^{21}$. La parte dedicada al Padre nuestro tocó a los franceses y a los franciscanos de Lovaina ${ }^{22}$. De los sacramentos como: el Bautismo, la Confirmación y la Eucaristía tenían que ocuparse los teólogos flamencos ${ }^{23}$. El sacramento de la Penitencia fue encomendado a Niccoló Ormanetto, teólogo de Verona ${ }^{24}$. Los restantes tres tenían que prepararlos teólogos españoles: el Matrimonio el dominico Pedro Fernández, el Orden Sacerdotal Cosme Damián de Hortolá clérigo secular y abad de Villabeltrán y la Extremaunción Benito Arias Montano teólogo de Martín Pérez de Ayala ${ }^{25}$. La preparación del Decálogo correspondió a los franceses, a los españoles y a los italianos. Sobre los cuatro primeros mandamientos tenían que trabajar los teólogos franceses, cuyos nombres no se conocen. Por los preceptos: quinto, sexto y séptimo tenían que ocuparse los tres dominicos. Respectivamente, el teólogo español Juan de Ludeña se encargó del quinto mandamiento, el italiano Benedetto Herba del sexto y Eliseo Capys, también italiano, del séptimo mandamiento ${ }^{26}$. El octavo mandamiento lo redactó el franciscano Alfonso de Contreras. Un teólogo de Granada, del cual no se conoce el nombre fue encomendado a preparar los comentarios de los dos últimos preceptos ${ }^{27}$. También se decidió, que el futuro

${ }^{19}$ Cf. P. Rodríguez, R. Lanzetti, El Catecismo Romano, pp. 59-60.

${ }^{20} \mathrm{Cf}$. H. Jedin, Geschichte des Konzils von Trient, Bd. 4: Dritte Tagunsperiode und Abschluss, Hlbd. 2: Überwindung der Krise durch Morone, Schliessung und Bestätigung, p. 238.

${ }^{21}$ Cf. P. Rodríguez, R. Lanzetti, El Catecismo Romano, p. 64.

${ }^{22}$ Ibídem.

${ }^{23}$ No se conocen los nombres de estos tres teólogos aunque Skibniewski se supone y parece aceptado por Paschini, que esos teólogos eran: Miguel Bayo, Juan Hessels y Cornelio Jansenio. El fundamento de esta idea es que éstos fueron los tres teólogos flamencos enviados al Concilio de Trento por Felipe II. No había otros teólogos flamencos en Trento. Ibídem, p. 64; y también G. Bedouelle, Das Entstehen des Catechismus, "Communio", 12 (1983) n. 1, p. 36; y también H. Jedin, Geschichte des Konzils von Trient, Bd. 4: Dritte Tagunsperiode und Abschluss, Hlbd. 2: Überwindung der Krise durch Morone, Schliessung und Bestätigung, p. 304.

${ }^{24}$ Cf. P. Paschini, Il Catechismo Romano del Concilio di Trento, Roma 1923, p. 14.

${ }^{25}$ Cf. P. Rodríguez, R. Lanzetti, El Catecismo Romano, p. 65; y también J. Ortiz, El sacramento del matrimonio en la exposición del Catecismo Romano, Pamplona 1981.

${ }^{26}$ Cf. P. Rodríguez, R. Lanzetti, El Catecismo Romano, p. 65.

${ }^{27}$ Skibniewski sugiere que éste fue probablemente Juan de Fonseca, teólogo de Pedro Guerrero, arzobispo de Granada. Cf. Ibídem, p. 66; y también R. Villoslada, Pedro Guerrero, representante de la reforma española en Il Concilio di Trento e la riforma tridentina. Atti del Convegno Storico Internazionale, Vicenza 1965. 
catecismo fuera editado en dos versiones, grande y pequeña. La primera tenía que estar destinada a los párrocos. Pero la segunda, siendo un resumen de la primera, tenía que estar adaptada al nivel intelectual de los niños y de la gente sencilla. Además, tenía que estar traducida a las lenguas nacionales como contrapeso a los catecismos heterodoxos ${ }^{28}$. Los respectivos teólogos trabajaron rápido y entregaron el material ya preparado a Gabriel Paleotti, cuya tarea fue resumirlo en latín ${ }^{29}$. En este modo se elaboró la primera redacción del futuro Catechismi Romani ${ }^{30}$. Sin embaro, al final, el Concilio de Trento no acabó la cuestión del catecismo. De ésta se encargó, junto con la revisión del Índice de libros prohibidos y con la reforma del misal y del breviario ${ }^{31}$, el papa Pío IV se obligó a finalizarlos lo más pronto posible. Con este objetivo, designó una nueva comisión, y tuvo como cometido elaborar el nuevo catecismo. Dentro de esta comisión se encontraban los teólogos más brillantes de aquella época, Muzio Calini arzobispo de Zara, Egidio Foscarari obispo de Módena, Leonardo Marini obispo de Lanciano y el teólogo portugués Francisco Foreiro que ya trabajó como secretario en la Comisión conciliar del Index ${ }^{32}$. Pero el más importante fue el cardenal Carlos Borromeo que se ocupó de la supervisión de todo el trabajo. Esta labor no duró mucho, sólo algunos meses. Del mismo modo que antes, también ahora el texto preparado fue devuelto a Julio Poggiani, uno de los mejores latinistas de aquella época. Gracias a él la obra alcanzó la unidad del estilo y la claridad. El catecismo ya fue preparado al final del año $1564^{33}$, pero su publicación, debido a motivos desconocidos, no tuvo lugar durante la vida del papa Pío IV ${ }^{34}$. El sucesor de Pío IV, el papa Pío V, tan pronto como fue elegido, nombró una Comisión la cual estuvo encabezada por el cardenal Guglielmo Sirleto y la ordenó hacer una revisión y corrección del texto ${ }^{35}$. Guglielmo Sirleto, excelente biblista y patrólogo, tenía que prestar atención, sobre todo, a la correspondencia de las citas de la Sagrada Escritura con las de la Vulgata y las citas de los Padres de la Iglesia con el contenido de donde provenían. En este trabajo lo ayudaron dos teólogos dominicos: el español Tomás Manrique y el boloñés Eustachio Locatelli ${ }^{36}$.

Los trabajos iban a buen ritmo y el día 23 de septiembre de 1566 fue publicada la primera edición latina titulada Catechismus ex decreto Concilii Tridentini de

${ }^{28}$ Cf. P. Paschini, Cinquecento romano e riforma cattolica, pp. 44-45.

${ }^{29}$ Ibídem, pp. 47-48.

${ }^{30}$ Cf. J. Z. Słowiński, Katechizmy katolickie w języku polskim, p. 90.

${ }^{31}$ Se habla sobre ellos en el quinto decreto de la vigésimoquinta congregación del Concilio del día 4 de diciembre de 1563. Cf. H. Jedin, Geschichte des Konzils von Trient, Bd. 4: Dritte Tagunsperiode und Abschluss, Hlbd. 2: Überwindung der Krise durch Morone, Schliessung und Bestätigung, pp. 186-187.

${ }^{32}$ Cf. P. Rodríguez, R. Lanzetti, El Catecismo Romano, p. 90. Cf. P. Paschini, Cinquecento romano e riforma cattolica, p. 50; y también A. Szorc, Korespondencja Stanistawa Hozjusza kardynała i biskupa warmińskiego, vol. 5, Año 1564, „Studia Warmińskie”, 13 (1976) p. 226.

${ }^{33}$ Cf. P. Paschini, Cinquecento romano e riforma cattolica, p. 49.

${ }^{34}$ Ibídem, p. 57.

${ }^{35}$ Cf. P. Rodríguez, R. Lanzetti, El Catecismo Romano, p. 117.

${ }^{36}$ Ibídem. 
Parochos Pii quinti Pont. Max. iussu editus ${ }^{37}$. Paulo Manuzio recibió el privilegio de impresión del papa y del rey español Felipe $\mathrm{II}^{38}$. Aparte del ejemplar ya escrito in-folio, de la oficina romana salieron otras cuatro ediciones latinas, in- $8^{\circ}{ }^{39}$. Dos aparecieron en el mismo año 1566 , otra en 1567 y otra en 1569. Al principio el nuevo catecismo no estuvo dividido en capítulos ni en partes. Por eso Pío V mandó introducirlos en las ediciones siguientes ${ }^{40}$. Este mandato no sólo se decretó por los aspectos prácticos, sino también por motivos polémicos, porque los catecismos protestantes ya contenían este esquema de división en partes y capítulos.

Casi simultáneamente con la versión latina, el Catecismo Romano empezó a ser traducido y editado en las lenguas nacionales ${ }^{41}$. Esto seguía la intención tanto del Concilio de Trento como del papa Pío V. Todavía en el mismo año que la edición típica latina, es decir 1566, fue publicada la versión italiana del dominico Alessio Figliucci titulada Catechismo cioè instruttione secondo il decreto del Concilio di Trento a Parochi pubblicato per comandamento del Santissimo S.N. Pio $V$ et tradotto ${ }^{42}$. En el año 1567 salieron dos traducciones francesas: una de Gentian Hervetus en París y otra anónima en Burdeos ${ }^{43}$. Pero la más significativa fue la primera traducción alemana realizada en 1568 por el jesuita Paulo Hoffaeus y revisada por Pedro Canisio. Esta traducción formaba parte de un plan del papa Pío V, que proyectaba la inmediata traducción del nuevo Catecismo no sólo al italiano, sino al alemán, francés y polaco ${ }^{44}$. La versión alemana fue importante porque la estructuración y compartimentación del texto respondieron mejor a la clara voluntad del papa Pío V, pero también porque precisamente en Alemania este catecismo por primera vez fue titulado Römischer Catechismus, es decir Catecismo Romano ${ }^{45}$.

${ }^{37}$ Cf. J. M. E. Llaurens, P. Rodríguez García, J. A. Gallego, Estudios sobre el Catecismo de la Iglesia Católica, Madrid 1996, p. 9.

${ }^{38}$ En la página principal de la edición típica fue escrito: Romae, in aedibus Populi Romani apud Paulum Manuntium MDLXVI. Cum privilegio Pii V. Pont. Max. et Philippi Hispaniarum Regis per unisersam Regni neapolitani editionem. Cf. P. Paschini, Cinquecento romano e riforma cattolica, Roma 1958, p. 64.

${ }^{39}$ Cf. P. Rodríguez, R. Lanzetti, El Catecismo Romano, p. 214; y también A. A. Renouard, Annales de l' imprimerie des Alde, ou histoire des trois Manuce et de leurs éditions, $3^{\mathrm{a}}$ ed., Paris 1834, pp. 200-230.

${ }^{40}$ Cf. P. Paschini, Cinquecento romano e riforma cattolica, p. 64.

${ }^{41}$ También fue traducido en árabe. Cf. M. Popielec, Katechizm kaliski i jego znaczenie dla polskich edycji Katechizmu Rzymskiego, Lublin 1970, p. 17.

${ }^{42}$ Cf. P. Rodríguez, R. Lanzetti, El Catecismo Romano, p. 214; y también P. Paschini, Cinquecento romano, pp. 65-66.

${ }^{43}$ Cf. P. Paschini, Cinquecento romano, p. 87.

${ }^{44}$ Cf. P. Rodríguez, R. Lanzetti, El Catecismo Romano, p. 228.

${ }^{45}$ El Catecismo de 1566 se conoce por varios nombres como: el Catecismo de San Pío V, el Catecismo del Concilio de Trento, el Catecismo para los párrocos, pero el título empleado con más frecuencia es el Catecismo Romano, precisamente debido a su traducción alemana de 1568. Cf. J. M. E. Llaurens, P. Rodríguez García, J. A. Gallego, Estudios sobre el Catecismo de la Iglesia Católica, Madrid 1996, pp. 9-10; y también B. Schneider, Hoffaeus Paul, Lexikon für Theologie und Kirche, vol. 5, Freiburg 1960, col. 415. 


\section{La estructura del Catecismo Romano}

Al principio en el Catecismo Romano no figuraba la división en partes y en capítulos. Todo el texto tenía carácter uniforme - páginas y páginas seguidas, sin puntos ni apartes ${ }^{46}$. Sólo por encargo del papa Pío V, en las siguientes ediciones se introdujo la división del texto, que ha llegado hasta nuestros días. Para que sea más fácil presentar la estructura de la obra, en este artículo, se utiliza la versión, que tiene esta división ${ }^{47}$.

El Catecismo Romano consta de cuatro partes principales - el Símbolo de la fe, los Sacramentos, el Decálogo, la Oración, y también de dos partes suplementarias - el Prefacio y el Index ${ }^{48}$. Y aunque cada parte está separada, todas construyen una sola obra. El mayor lugar lo ocupa la parte dedicada a los sacramentos. Esto está claro, porque precisamente alrededor del tema de los sacramentos se concentraba la polémica con los protestantes. Los autores del catecismo queriendo presentar la plena doctrina católica de los sacramentos, necesitaron hacer referencia a la Sagrada Escritura y la Tradición y ésto influyó en la expansión de este capítulo. En lo referente al tamaño, el siguiente puesto está ocupado por el Decálogo. Los autores también dieron gran importancia al Símbolo y al tema de la oración, dedicándoles muchas páginas. Los demás, el Prefacio y el Index constituyen sólo un suplemento a las cuatro piezas fundamentales.

El Prefacio tiene como objetivo introducir al lector en pleno Catecismo. Por eso empieza por el tema de las capacidades y límites del hombre en su esfuerzo en la conquista de Dios ${ }^{49}$. El hombre no está destruído por completo, como predicaron los protestantes, pero al mismo tiempo necesita la Revelación para conocer a Dios. Luego los autores pasan al tema de la necesidad de la predicación de la fe, mostrando que Dios, en su gran bondad, elige algunos hombres y hace de ellos sus instrumentos. Estos hombres actuando, no actúan por su propia autoridad, sino por la autoridad de Dios, por eso son dignos de obediencia ${ }^{50}$. Su misión y deber son siempre actuales, pero mucho más en los tiempos de los pseudoprofetas que envenenan las almas con extrañas y falsas doctrinas ${ }^{51}$. Según los autores, los nuevos métodos, que usan estos corruptores del espíritu cristiano ${ }^{52}$, exigen una respuesta de la parte católica. De este modo los autores muestran la causa de la elaboración del Catecismo y también los objetivos que tiene que cumplir.

${ }^{46}$ Cf. P. Rodríguez, R. Lanzetti, El Catecismo Romano, pp. 210-211.

${ }^{47}$ En este artículo he utilizado la edición crítica del Catecismo Romano realizada por Pedro Rodríguez, Ildefonso Adeva, Francisco Domingo, Raúl Lanzetti y Marcelo Merino - Catechismus Romanus, Libreria Editrice Vaticana / Ed. Universidad de Navarra, Città del Vaticano 1989. Citada en adelante: CR-editio critica.

${ }^{48}$ Cf. CR-editio critica, p. IX.

49 "Ea est humanae mentis et intelligentiae ratio, ut, cum alia multa quae ad divinarum rerum cognitionem pertinent (...).” CR-editio critica, pp. 5-6.

50 "Ac ne quis verbum auditus Dei ab Ecclesiae ministris, tamquam verbum hominum, sed, sicut vere est, verbum Christi acciperet, ille ipse Salvator noster tantam auctoritatem eorum magisterio tribuendam esse statuit (...)." CR-editio critica, pp. 6-7.

${ }^{51}$ CR-editio critica, p. 7.

${ }^{52}$ Ibídem. 
Su meta principal es dar a conocer la figura de Jesucristo. ${ }^{53}$ Además, los autores hablan de la importancia de imitar a Cristo y cumplir la ley del amor. La siguiente parte del Prefacio está dedicada al tema conocido desde los tiempos de san Agustín, es decir, al tema de la necesidad de adaptar los métodos de la enseñanza al nivel y capacidad de los oyentes. Los sacerdotes, que toman como responsabilidad esta enseñanza tienen que darse cuenta de que no todas las almas se encuentran al mismo nivel ${ }^{54}$. En la pregunta, dónde está contenida esta enseñanza, los autores responden en el mismo modo que el Concilio de Trento, indicando las dos fuentes de la Revelación - la Sagrada Escritura y la Tradición ${ }^{55}$. La última parte del Prefacio introduce al lector en las siguientes cuatro piezas del Catecismo - el Credo, los Sacramentos, el Decálogo y la Oración explicando brevemente el contenido de cada uno de éstos.

La primera parte del Catecismo Romano, como ya se ha adelantado, está dedicada al Símbolo de la fe ${ }^{56}$. Consta de doce capítulos, de los cuales, cada uno se refiere a una parte del Símbolo ${ }^{57}$. Según los autores del Catecismo creer no significa lo mismo que pensar, juzgar, opinar ${ }^{58}$, ni estar conforme con su punto de vista. Refiriéndose a la Sagrada Escritura, los autores muestran la fe como una aprobación con la cual, la mente sin cesar y en modo estable, se adhiere a Dios. Aunque no se ven estas realidades, que la fe ofrece, no hay que pensar, que el conocimiento a través de la fe no es seguro. Porque la luz de Dios, que ha sido dada a cada hombre, permite creer en ellas sin vacilaciones ${ }^{59}$. Esta idea muestra claramente, que el Catecismo Romano siendo fiel a las indicaciones del Concilio de Trento, no quitó por completo la terminología escolástica, como lo hizo Lutero, sino que supo armonizar el vocabulario bíblico con el vocabulario teológico ${ }^{60}$. Todo lo que se refiere al Padre, al Hijo y al Espíritu Santo los autores lo presentan en los capítulos I-VIII ${ }^{61}$. En el capítulo noveno desarrollan el tema de la Iglesia y le prestan gran atención. Precisamente éste tema fue objeto de una fuerte crítica

53 "Haec est vita aeterna, ut cognoscant te, solum verum Deum, et quem misisti, Iesum Christum. Quamobrem in eo praecipue ecclesiastici doctoris opera versabitur, ut fideles scire ex animo cupiant Iesum Christum, et hunc crucifixum." CR-editio critica, p. 9.

${ }^{54}$ CR-editio critica, p. 11.

55 "Omnis autem doctrinae ratio quae fidelibus tradenda sit verbo Dei continetur, quod in Scripturam Traditionesque distributum est." CR-editio critica, p. 12.

${ }^{56}$ Cf. P. Rodríguez, El Catecismo de la Iglesia Católica: interpretación histórico-teológica. Lección inaugural del curso académico 1994-1995 en la Universidad de Navarra, Pamplona 1994, p. 24.

${ }^{57}$ Cf. CR-editio critica, pp. 19-149.

58 "Igitur credendi vox hoc loco putare, existimare, opinari non significat." Cf. CR-editio critica, p. 21.

59 "(...) contra vero illa humanae mentis aciem ita exacuit, ut in caelum nullo labore penetrare possit atque, divino splendore collustrata, primum quidem aeternum ipsum luminis fontem, deinde, quae infra ipsum posita sunt intueri, ut nos vocatos esse de tenebris in admirabile lumen (...)." CR-editio critica, p. 23.

${ }^{60}$ Cf. A. Etchegaray-Cruz, Storia della catechesi, Roma 1984, pp. 210-211.

${ }^{61}$ Cf. CR-editio critica, pp. 21-102. 
por parte de los reformadores protestantes ${ }^{62}$. Los autores del Catecismo hablan sobre la Iglesia con perspectiva bíblico-patrística. Para ellos la Iglesia es, sobre todo, un llamamiento ${ }^{63}$. En la Sagrada Escritura el término Ecclesia significa una sociedad cristiana y una asamblea de los fieles, es decir, todos los que a través de la fe son llamados a: conocer al Dios verdadero, alabarlo y glorificarlo por la vida santa y servirlo de todo corazón ${ }^{64}$. Además de estas definiciones, los autores también usan en el texto del Catecismo citas que provienen de las obras de los Padres de la Iglesia. Especialmente citan a san Agustín según el cual, la Iglesia significa el pueblo fiel esparcido por todo el mundo ${ }^{65}$. En la siguiente parte del texto los autores analizan los términos bíblicos que se refieren a la Iglesia, hablan sobre la Iglesia terrestre y celestial, quién la constituye y qué atributos tiene ${ }^{66}$.

El Concilio de Trento dió a todo el trabajo pastoral una orientación sacramenta ${ }^{67}$. La causa de esto fue la doctrina de los protestantes la cual basándose sólo en la Sagrada Escritura, aceptó el Bautismo y la Eucaristía, rechazando los sacramentos restantes. Esta orientación también está destacada en el Catecismo Romano, donde la segunda parte titulada De Sacramentis es más amplia ${ }^{68}$. Los autores del Catecismo, apoyándose en la doctrina de santo Tomás de Aquino, colocan la parte dedicada a los sacramentos inmediatamente después del Credo ${ }^{69}$. Cada sacramento está tan detalladamente descrito, que se puede tratar esta parte del Catecismo como un ritual. Para que la doctrina de los sacramentos fuese más comprensible, los autores aprovecharon la teoría del signo ${ }^{70}$. Así entendió el sacramento san Agustín y precisamente de él la copiaron los autores del Catecismo ${ }^{71}$. Además de la idea del signo, los autores tratan los motivos por los que se instauraron los

\footnotetext{
${ }^{62}$ Cf. J. Z. Słowiński, Katechizmy katolickie w języku polskim, p. 112.

${ }_{63}$ "Significat autem ecclesia evocationem, verum scriptores postea usurparunt pro concilio et concione." CR-editio critica, p. 104.

${ }_{64}$ "Communi vero deinde sacrarum Scripturarum consuetudine haec vox ad rempublicam christianam fideliumque tantum congregationes significandas usurpata est, qui scilicet ad lucem veritatis et Dei notitiam per fidem vocati sunt, ut, reiectis ignorantiae et errorum tenebris, Deum verum et vivum pie et sancte colant illique ex todo corde inserviant." CR-editio critica, pp. 104-105.

${ }_{65}$ "Ecclesia, ut ait sanctus Augustinus, est populus fidelis per universum orbem dispersus." CR-editio critica, p. 105.

${ }^{66}$ Cf. CR-editio critica, pp. 105-121.

${ }^{67}$ Cf. J. Z. Słowiński, Katechizmy katolickie w języku polskim, p. 112.

${ }^{68}$ En la edición crítica realizada por Pedro Rodríguez, Ildefonso Adeva, Francisco Domingo, Raúl Lanzetti y Marcelo Merino la parte dedicada a los sacramentos ocupa 240 páginas. Cf. CR-editio critica, pp. 153-393.

${ }^{69}$ Cf. A. Etchegaray-Cruz, Storia della catechesi, Roma 1984, p. 208.

70 "Quae quidem definitio ut magis pateat, singulae eius partes pastoribus exponendae erunt." CR-editio critica, p. 156.

71 "Sacramenta enim ex genere earum rerum esse quibus salus et iustitia comparatur, dubitare nemo potest. Sed cum multae rationes sint quae ad hanc rem explicandam aptae et accommodatae videantur, nulla tamen planius et dilucidius eam demonstrat quam definitio a divo Augustino tradita, quam deinde omnes doctores scholastici secuti sunt: Sacramentum, inquit ille, est signum rei sacrae; vel, ut aliis verbis, in eandem tamen sententiam, dictum est: Sacramentum est invisibilis gratiae visibile signum ad nostram iustificationem institutum." CR-editio critica, pp. 155-156.
} 
sacramentos $^{72}$, la materia y la forma de cada uno de ellos ${ }^{73}$, también presentan las diferencias entre los sacramentos del Antiguo y del Nuevo Testamento, muestran los ritos y reflexionan sobre el número de sacramentos ${ }^{74}$. En lo que concierne a la cuestión del número de los sacramentos y su necesidad, los autores aprovechan la analogía con las etapas de la vida humana. Algunos sacramentos provocan la vida espiritual, otros la conservan, otros hacen la vida útil para uno mismo y para la Iglesia ${ }^{75}$. A continuación, en los siete capítulos siguientes muestran cada sacramento según un esquema constante. Empiezan con la necesidad e importancia del estudio del sacramento en particular y pasan por su noción etimológica, su naturaleza, su institución, materia y forma, sus ministros, su utilidad, los efectos que produce, las ceremonias en su administración y terminan con más conclusiones ${ }^{76}$. Entre los siete sacramentos los autores prestan más atención a la Eucaristía y a la Penitencia. La Eucaristía, la comentan aprovechando la ocasión del sacrificio de la misa. Tocan también uno de los temas más importantes en la polémica con los protestantes, ésto es, la comunión bajo dos especies. Compartiendo la opinión del Concilio de Trento, se declaran a favor de la comunión bajo una especie. Al mismo tiempo aportan los argumentos para los sacerdotes que son responsables de la formación de los fieles y recomiendan enseñarlos asi ${ }^{17}$. En la Eucaristía, entendida como liturgia, los autores casi por completo omiten su dimensión existencial. Los teólogos dominicos entienden los sacramentos de la misma manera que su maestro santo Tomás, sólo desde el punto de vista de la esencia de la realidad. Por eso en la misa, la parte más importante para ellos es la consagración y dentro de ella, la transubstanciación. Esta idea deja de lado la comprensión de la Eucaristía como presencia del misterio pascual de Cristo ${ }^{78}$. En el capítulo cuarto, dedicado al sacramento de la Penitencia el primer puesto lo ocupa la doctrina sobre la confesión ${ }^{79}$. Precisamente esta doctrina, con su concepción jurídico-legal del pecado, tenía mayor influencia en la teología postridentina. El pecado está comprendido en el texto como una infracción consciente y voluntaria del mandamiento divino

${ }^{72}$ Cf. CR-editio critica, pp. 161-164.

${ }^{73} \mathrm{Cf}$. CR-editio critica, pp. 164-165.

${ }^{74} \mathrm{Cf}$. CR-editio critica, pp. 166-167.

75 "Cur autem neque plura neque pauciora numerentur, ex iis etiam rebus quae per similitudinem a naturali vita ad spiritualem transferuntur, probabili quadam ratione ostendi poterit. Homini enim ad vivendum, vitamque conservandam, et ex sua reique publicae utilitate traducendam, haec septem necessaria videntur: ut scilicet in lucem edatur, augeatur, alatur; si in morbum incidat, sanetur; imbecillitas virium reficiatur; deinde, quod ad rempublicam attinet, ut magistratus numquam desint, quorum auctoritate et imperio regatur; ac postremo, legitima sobolis propagatione se ipsum et humanum genus conservet." CR-editio critica, p. 167.

${ }^{76}$ Cada uno de los siete sacramentos guarda estos puntos, pero no siempre siguiendo el mismo orden. Por ejemplo en el caso de Eucaristía, el Catecismo Romano primero habla sobre la necesidad e importancia del estudio de este sacramento, después trata sobre la institución y luego sobre la noción etimológica. Cf. CR-editio critica, pp. 235-238.

${ }^{77}$ Cf. J. Mielczarek, Komunia pod dwiema postaciami w ustawodawstwie Kościoła Zachodniego, Lublin 1983, p. 138.

${ }^{78}$ Cf. A. Etchegaray-Cruz, Storia della catechesi, p. 213.

${ }^{79}$ Cf. CR-editio critica, pp. 309-325. 
o eclesial. En las páginas sucesivas los autores catalogan los pecados según sus tipos, comentan sus formas, grados y circunstancias ${ }^{80}$. En este contexto, la confesión misma se asemeja a un proceso, donde el papel del juez lo hace el confesor, el penitente es el acusado, y los pecados son el objeto de la acusación ${ }^{81}$. La absolución, que da el confesor en nombre de Jesucristo libera al penitente de la culpa que merece la pena eterna, pero se queda la cuestión de la pena temporal ${ }^{82}$. Ésta en el Catecismo está identificada con la penitencia, la cual es dada por el confesor al penitente. A su vez, la penitencia se junta con la doctrina de las indulgencias contra la cual se alzó Lutero. Uniendo la cuestión de la penitencia con la de las indulgencias, los autores del Catecismo muestran la posibilidad de sustituir la pena por las indulgencias, que evitan al penitente la dimensión pública de la penitencia ${ }^{83}$. Resumiendo en la segunda parte del Catecismo se puede decir que el hecho de haber colocado demasiado acento en algunas cuestiones, especialmente en estas que se referían al sacramento de la Eucaristía y al sacramento de la Penitencia, el Catecismo Romano en realidad entró en la polémica con los protestantes.

La parte dedicada a los diez preceptos ocupa en el Catecismo Romano los diez siguientes capítulos ${ }^{84}$. El primer capítulo títulado De Decalogo divinisque legibus constituye una corta introducción ${ }^{85}$. Los demás tratan de los diez mandamientos en particular: el capítulo segundo titulado Non habebis deos alienos coram me habla del primer mandamiento, el tercero Non assumes nomen Domini Dei tui in vanum del segundo mandamiento, el cuarto Memento ut diem sabbati sanctifices ${ }^{86}$ del tercer mandamiento, el quinto Honora patrem tuum et matrem tuam; ut sis longaevus super terram, quam Dominus Deus tuus dabit tibi del cuarto precepto, el capítulo sexto Non occides del quinto precepto, el séptimo Non moechaberis del sexto mandamiento, el octavo Non furtum facies del séptimo precepto, el noveno Non loqueris contra proximum tuum falsum testimonium del octavo mandamiento y el capítulo décimo titulado Non concupisces domum proximi tui; nec desiderabis uxorem eius, non servum, non ancillam, non bovem, non asinum,

${ }^{80}$ Cf. CR-editio critica, pp. 317-320.

${ }^{81}$ Cf. J. Z. Słowiński, Katechizmy katolickie w języku polskim, p. 114.

82 "Docendi enim sunt duo esse quae peccatum consequuntur, maculam et poenam. Ac quamvis semper, culpa dimissa, simul etiam mortis aeternae supplicium apud inferos constitutum condonetur, tamen non semper contingit, quemadmodum a Tridentina Synodo declaratum est, ut Dominus peccatorum reliquias et poenam certo tempore definitam, quae peccatis debetur, remittat." CR-editio critica, p. 328.

${ }^{83}$ Cf. J. Z. Słowiński, Katechizmy katolickie w języku polskim, p. 115.

${ }^{84}$ Como he mencionado antes, al comienzo el Catecismo Romano no estuvo dividido en capítulos, ni en partes, pero por el mandato del Papa Pío V en las ediciones consecutivas ya se introdujo esta división. Lo muestran bien P. Rodríguez y R. Lanzetti en su libro El Catecismo Romano: fuentes e historia del texto y de la redacción. Pamplona 1982, p. 211.

${ }^{85}$ Cf. CR-editio critica, pp. 397-407.

${ }^{86}$ El título completo es: Memento ut diem sabbati sanctifices. Sex diebus operaberis, et facies omnia opera tua. Septima autem die sabbatum Domini Dei tui est. Non facies omne opus in eo tu, et filius tuus et filia tua, servus tuus et ancilla tua, iumentum tuum, et advena qui est intra portas tuas. Sex enim diebus fecit Dominus caelum et terram, mare, et omnia quae in eis sunt, et requievit in die septimo; idcirco benedixit Dominus diei sabbati, et sanctificavit eum. CR-editio critica, p. 438. 
nec omnia quae illius sunt trata en conjunto del noveno y décimo mandamiento. Todos los mandamientos del Catecismo Romano llevan el mismo esquema, aunque no todos estuvieron elaborados por el mismo autor. Como lo he mencionado antes, los cuatro primeros fueron preparados por los teólogos franceses, los tres siguientes por los teólogos dominicos, el octavo por el franciscano Alfonso de Contreras y los dos últimos probablemente por el obispo Juan de Fonseca ${ }^{87}$. Pues en realidad, cada uno de los diez mandamientos fue dispuesto por un teólogo distinto, sin embargo, no le molestó conservar el esquema interior de la obra. Al comienzo de cada mandato se explica el significado y el valor del precepto. Por ejemplo en el caso del segundo mandamiento el autor remarca quiso, no obstante, el Señor explicitar este mandamiento, para señalarnos la suma importancia que Él atribuye al deber de tributar el honor y respeto que le son debidos a su divino y santísimo nombre ${ }^{88}$. Además de la exposición general algunos autores aprovechan este espacio para acentuar la autoridad del mandamiento, a través de las referencias al pasado. Es un medio pedagógico que tiene un fin de animar a los fieles al cumplimiento del mandato. El razonamiento va a ser el siguiente: tengo que guardar los preceptos porque lo mismo hicieron mis antepasados. La siguiente frase lo muestra muy bien: que este séptimo mandamiento se explicaba con frecuencia a los fieles ya en los primeros tiempos de la Iglesia, lo demuestran aquellas palabras del Apóstol ${ }^{89}$. En la introducción a la explicación de los preceptos los teólogos usan frecuentemente también los textos bíblicos. Al inicio del noveno y décimo mandamientos el autor escribe, citando la Carta a Timoteo: porque, según la Escritura, la raíz de todos los males es la avaricia, y muchos, por dejarse llevar de ella, se extravían en la fe y a sí mismos se atormentan con muchos dolores ${ }^{90}$. Además de todo lo mencionado, la introducción a cada precepto sirve para demostrar la unidad interna del texto decalogal. Los autores del Catecismo Romano siguiendo toda la tradición cristiana y judía dividen los diez mandamientos en dos grupos ${ }^{91}$. El primer grupo lo forman los tres primeros preceptos de la primera tabla, que se refieren a Dios. El segundo grupo lo representan los otros siete mandatos que están situados en la segunda tabla y tienen como objeto el hombre. El prefacio al primer mandamiento destaca este aspecto muy bien: $L a$ primera parte del decálogo contiene los tres mandamientos que se refieren a Dios,

${ }^{87}$ P. Rodríguez y R. Lanzetti en su libro El Catecismo Romano: fuentes e historia del texto y de la redacción, desarrollan este tema.

88 "Deus tamen pro rei magnitudine hanc de suo ipsius divino et sanctitatis plenissimo nomine honorando legem separatim ferre, idque nobis disertis et perspicuis verbis praescribere voluit." CR-editio critica, p. 423.

89 "Veterem hunc Ecclesiae morem fuisse, ut huius praecepti vis et ratio inculcaretur auditoribus, indicat illa apud Apostolum obiurgatio eorum, quie ceteros ab iis vitiis maxime deterrerent, quibus ipsi cumulati reperiebantur." CR-editio critica, p. 485.

90 "Nam stirps ac semen malorum omnium est prava concupiscentia, qua qui incensi sunt, praecipites feruntur in omne flagitiorum et scelerum genus." CR-editio critica, p. 513.

${ }^{91}$ Sobre la división de los mandamientos en dos grupos y su significado en el tiempo patrístico C.f. M. Lluch-Baixauli, Formación y evolución del tratado escolástico sobre el decálogo (11151230), Louvain 1997, pp. 75-76. 
y en la segunda siguen lógicamente los que se refieren al prójimo ${ }^{92}$. Explicando por qué es así los autores usan la argumentación patrística y dicen que sólo en Dios se encuentra la razón de todo cuanto debemos hacer por el prójimo; entonces amamos cristianamente al prójimo cuando lo hacemos por amor de Dios ${ }^{93}$. Según los autores la distinción de los objetos decide que los mandamientos de la primera tabla son superiores a los de la segunda. Ésto lo confirma el prefacio del cuarto precepto: si es grande la excelencia de los tres primeros mandamientos, superiores a todos los demás por la sublime dignidad de su objeto, Dios, también son necesarios para la vida cristiana los siete restantes ${ }^{94}$. Tras la presentación, por lo general, los autores explican detalladamente el aspecto positivo y negativo (duplex praecepti pars) de cada uno de los mandamientos. Por el aspecto positivo entienden todo lo que Dios como sumo legislador, en función del precepto concreto, obliga positivamente a hacer. En el caso del primer mandamiento es el honor y respeto debido a Él, único Dios verdadero ${ }^{95}$. En el del segundo el honor al santo nombre de Dios ${ }^{96}$. En el del tercero la santificación del día del Señor ${ }^{97}$. En el del cuarto la honra al padre y a la madre ${ }^{98}$. En el del quinto mandamiento el aspecto positivo lo constituyen la caridad, la concordia y la paz con todos, aún con los enemigos ${ }^{99}$. En el del sexto la castidad del alma y del cuerpo ${ }^{100}$. En el del séptimo la caridad y la generosidad con el prójimo ${ }^{101}$. En el del octavo la verdad en todas nuestras palabras y acciones ${ }^{102}$. Y en del último, doble precepto, la lucha contra la concupiscencia ${ }^{103}$. El aspecto negativo de cada mandato forma lo que Dios prohibe hacer. Comenzando desde el primer precepto y recorriendo todos los demás, el aspecto negativo representa el pecado de idolatría ${ }^{104}$, el falso juramento ${ }^{105}$, el trabajo en los días del Señor ${ }^{106}$, la desobediencia a los padres y autoridades ${ }^{107}$,

92 "Priorem in Decalogo locum obtinere quae ad Deum pertinent, posteriorem vero quae ad proximum." CR-editio critica, p. 408.

93 "Docebit parochus, quia eorum, quae proximo praestamus causa Deus est; tum enim ex Dei praecepto proximum diligimus, cum propter Deum diligimus." Cf. CR-editio critica, p. 408.

${ }_{94}$ "Cum in superioribus praeceptis summa sit vis et dignitas, merito, quae nunc persequimur, quia maxime necessaria sunt, proximum locum obtinent.” CR-editio critica, p. 451.

${ }^{95}$ CR-editio critica, pp. 408-414.

${ }^{96}$ CR-editio critica, pp. 424-433.

${ }^{97}$ CR-editio critica, pp. 442-447.

${ }^{98}$ CR-editio critica, pp. 454-461.

${ }^{99}$ CR-editio critica, pp. 470-475.

${ }^{100}$ CR-editio critica, pp. 479-484.

${ }^{101}$ CR-editio critica, pp. 492-496.

${ }^{102}$ CR-editio critica, pp. 507-509.

${ }^{103}$ CR-editio critica, pp. 521-523.

${ }^{104}$ CR-editio critica, pp. 414-422.

${ }^{105}$ CR-editio critica, pp. 433-437.

${ }^{106}$ CR-editio critica, pp. 447-450.

${ }^{107}$ CR-editio critica, pp. 461-463. 
el homicidio ${ }^{108}$, el adulterio y todo el pecado deshonesto ${ }^{109}$, el robo y la rapiña ${ }^{110}$, los falsos testimonios y mentiras ${ }^{111}$, la concupiscencia ${ }^{112}$. Investigando con atención el número de las sucesivas páginas referidas a lo que está prohibido y a lo que está mandado, se puede descubrir una cierta dependencia. En los mandamientos: primero, segundo, tercero y cuarto, el aspecto positivo se explica al principio y tras él, el aspecto negativo, mientras que, en los preceptos siguientes, es al revés. A partir del quinto, los autores empiezan la explicación por el aspecto negativo para luego pasar al aspecto positivo. Esta modificación, aunque muy clara, no afecta en ninguna manera al texto decalogal. Duplex praecepti pars constituye cada uno de los mandamientos y parece que sólo de los autores dependía si su explicación comenzaría con un aspecto positivo o negativo.

Para los autores del Catecismo Romano, del mismo modo que para varios autores cristianos anteriores, el fundamento de la oración lo constituye la esperanza. Las sucesivas peticiones del Padre nuestro responden, según estos autores, a los objetivos de la esperanza cristiana. Por eso la cuarta parte del Catecismo dedicada a la oración tiene este esquema. Los primeros nueve capítulos los ocupa una gran introducción, donde están explicadas las siguientes cuestiones: la necesidad de la oración, sus frutos, sus distintos tipos y la parte práctica de la oración ${ }^{113}$. Los siguientes ocho capítulos se refieren a las ocho sucesivas peticiones del Padre nuestro ${ }^{114}$. El Catecismo Romano vuelve al auténtico sentido de la oración cristiana que estuvo presente en la tradición bíblico-patrística, esto es, a la oración de alabanza ${ }^{115}$. Según los autores el primer fruto de la oración es el honor y la alabanza que se rinde al mismo Dios ${ }^{116}$. Dirigiéndose a Él se manifiesta, que Él es el autor de todas la cosas creadas y por eso es digno de gloria y de alabanza ${ }^{117}$. El segundo fruto de la oración, según el Catecismo, es el saber que nuestras súplicas son escuchadas por Dios ${ }^{118}$. Y solamente de ésto surgen los siguientes: los dones del Espíritu Santo, la conservación e incolumidad de la fe, la exención de las penas, la defensa de las tentaciones, la victoria del demonio y las alegrías más

${ }^{108}$ CR-editio critica, pp. 465-470.

${ }^{109}$ CR-editio critica, pp. 477-479.

${ }^{110}$ CR-editio critica, pp. 486-492.

${ }^{111}$ CR-editio critica, pp. 501-507.

${ }^{112}$ CR-editio critica, pp. 516-521.

${ }^{113}$ Cf. CR-editio critica, pp. 527-555.

${ }^{114}$ Cf. CR-editio critica, pp. 569-646.

115 "Quare nos hac ratione Deo subiectos esse profitemur, quem bonorum omnium auctorem agnoscimus et praedicamus, in quem solum spectamus, quod unum incolumitatis salutisque praesidium atque perfugium habemus. Huius fructum illis etiam verbis admonemur: Invoca me in die tribulationis, eruam te, et honorificabis me." CR-editio critica, p. 530.

116 "Primus autem fructus quem inde capimus est is, quod orantes Deo honorem habemus; siquidem est quoddam religionis argumentum oratio, quae in divinis Litteris thymiamati comparatur. Dirigatur enim, inquit Propheta, oratio mea sicut incensum in conspectu tuo." CR-editio critica, p. 530.

${ }^{117}$ Cf. A. Etchegaray-Cruz, Storia della catechesi, p. 210.

${ }^{118}$ CR-editio critica, p. 530. 
bellas de la vida espiritual ${ }^{119}$. La vuelta a la tradición bíblico-patrística, especialmente a los Padres de la Iglesia, san Ignacio de Antioquía y san Agustín, también está presente en el párrafo dedicado a la práctica de la oración. De acuerdo con el Catecismo, la primera disposición esencial para orar es tener un espíritu verdaderamente humilde, consciente y arrepentido de los propios pecados ${ }^{120}$. Además de esto recomienda la necesidad del dolor de los pecados, o al menos un sentimiento de desagrado, la fe, sin la cual no se puede tener un verdadero conocimiento de Dios y de su misericordia, la esperanza, generadora de toda confianza y por último la certeza máxima de ser escuchados por Dios ${ }^{121}$. Seguido de la presentación del aspecto práctico de la oración los autores, en los siguientes ocho capítulos exponen las siguientes peticiones del Padre Nuestro juntándolos sobre todo con la virtud de la esperanza ${ }^{122}$. El último capítulo de la cuarta parte está dedicado a la palabra amen, la cual san Jerónimo en sus Comentarios a san Mateo llama sello final del Padrenuestro ${ }^{123}$.

Resumiendo, la estructura del Catecismo Romano, consta de cuatro grandes piezas, que ya desde la época patrística componían la catequesis de la Iglesia ${ }^{124}$. El Símbolo de la fe, el Decálogo, los Sacramentos y la Oración servían de base a la mayoría de los manuales destinados a la enseñanza catequética, pues no extraña entonces, que en el año 1566 estos elementos formaran parte del primer catecismo oficial de la Iglesia Católica. Sin embargo la comparación de la estructura del Catecismo Romano con el orden de los principales catecismos que lo preceden, tanto católicos, como heterodoxos, muestra una particularidad. Esta originalidad consiste, sobre todo, en la composición de la obra, es decir, en el modo de ordenar las cuatro grandes piezas dentro del mismo catecismo ${ }^{125}$. ¿Cuál fue el orden del Catecismo Romano y cuál fue el probable significado de este esquema? Esto es explicado a continuación.

119 "Cuius orandi muneris tanta vis est, tanta utilitas, ut ea re caelestium donorum amplitudinem consequamur. Nam et impetramus nobis ut ducem et adiutorem adhibeat Spiritum Sanctum; et fidei assequimur conservationem et incolumitatem, et vitationem poenarum, et divinum patrocinium in tentationibus, et ex diabolo victoriam." CR-editio critica, p. 531.

120 "Primus igitur gradus ad orationem erit vere humilis ac demissus animus, scelerum quoque recognitio." CR-editio critica, p. 546.

${ }^{121}$ Cf. CR-editio critica, pp. 547-550.

${ }^{122}$ Cf. CR-editio critica, pp.556-641.

123 "Hanc vocem, sicuti est, signaculum orationis dominicae appellat sanctus Hieronymus in commentariis in Matthaeum." CR-editio critica, p. 642.

${ }^{124}$ Cf. P. Rodríguez, El Catecismo de la Iglesia Católica, p. 24.

${ }^{125}$ Es necesario decir, que en el Symbolum sive Catechismus de Erasmo de Rotterdam y en el Catechismus Catholicus de Federico Nausea se contienen ya intuiciones en la línea del Catecismo Romano. Cf. J. M. E. Llaurens, P. Rodríguez García, J. A. Gallego, Estudios sobre el Catecismo de la Iglesia Católica, Madrid 1996, p. 14; y también Cf. P. Rodríguez, R. Lanzetti, El manuscrito original del Catecismo Romano. Descripción del material y los trabajos al servicio de la edición crítica del Catecismo del Concilio de Trento. Pamplona 1985, pp. 25-31. 


\section{El significado del orden del Catecismo Romano en las controversias teo- lógicas del siglo XVI}

Aunque desde la época patrística, la catequesis de la Iglesia constaba de cuatro grandes piezas, el símbolo, la oración, los sacramentos y el decálogo ${ }^{126}$, no había un esquema catequético fijo. Cada autor, al crear su obra, se servía de un esquema propio. Incluso, durante los primeros siglos del cristianismo existían manuales, que ni siquiera constaban de las cuatro partes, las cuales en la actualidad las consideramos imprescindibles. Lo más frecuente era encontrar fuera de eso a los diez mandamientos, relacionados al principio solamente con los comentarios de los sermones y del texto bíblico. Es sólo desde el período medieval, a partir del siglo XII, que en las grandes escuelas catedralicias empezaron a surgir las primeras sistematizaciones teológicas que abarcaron toda la doctrina de la Iglesia ${ }^{127}$. Ante todo, la organización del trabajo de la enseñanza y de la especulación teológica tuvo un enorme crecimiento a comienzos del siglo XIII y en el mundo universitario nacieron nuevos géneros literarios, las grandes Sumas de la Teología. Aunque trataron de la fe, de los sacramentos, de la oración y del decálogo, el esquema catequético presentado por ellas, todavía era muy lejano al del orden contenido en el Catecismo Romano. Por ejemplo la gran Suma de la Teología de santo Tomás de Aquino, escrita en los años 1268-1273, fue dividida en una gran simplificación, según el orden la fe - la oración - el decalogo - los sacramentos ${ }^{128}$. Pronto, el esquema catequético de santo Tomás llegó a ser un esquema emblemático para mayoría de las obras posteriores. Si se quería escribir algún libro catequético, con el fin de que su divulgación alcanzara renombre, había que dedicar la primera parte de este libro a la confessio fidei, la segunda parte al paternoster y las siguientes reservarlas para las cuestiones morales y los sacramentos ${ }^{129}$. Por ejemplo, así las llamadas tablas catequéticas que surgieron en Alemania en el siglo XV, que fueron destinadas a la gente sencilla y gozaban de una gran popularidad presentaron el siguiente orden: el credo - el padre nuestro - los diez mandamientos - los siete sacramentos - el angelus - el catálogo de las virtudes y de los pecados ${ }^{130}$. La dominación del esquema catequético de santo Tomás se interrumpió a partir del año 1566, es decir, desde la primera edición del Catecismo Romano. Es verdad, que algunas obras catequéticas pretridentinas, como por ejemplo el Symbolum sive Catechismus de Erasmo de Rotterdam de 1533 y el Catechismus Catholicus

${ }^{126}$ Ibídem, p. 24.

${ }^{127}$ Varios factores influyeron al gran desarrollo intelectual en Europa a partir del siglo XII. Ante todo se había conseguido la paz en la querella de las investiduras por el Concordato de Worms de 1122. En el año siguiente el Papa Calixto II, aprovechando la buena coyuntura, convocó el I Concilio de Letrán. Francia, aunque quedó reducida a un mínimo territorio cuyo centro era la Isla de Francia, todo el tiempo se desarrollaba. Con el reinado de Felipe II Augusto, que fue el gran impulsor de las catedrales y de la Universidad parisina, Francia empezó ampliar sus territorios hacia el sur. C.f. J. L. Illanes, J. I. Saranyana, Historia de la Teología, Madrid 1996, pp. 25-26.

${ }^{128}$ Cf. J. L. Illanes, J. I. Saranyana, Historia de la Teología, pp. 64-72.

${ }^{129}$ Cf. J. Wolny, Z dziejów katechezy, Dzieje teologii katolickiej w Polsce, vol. 1, Lublin 1974, p. 165.

${ }^{130}$ Cf. J. Z. Słowiński, Katechizmy katolickie w języku polskim, p. 58. 
del obispo de Viena Federico Nausea marcaron ya las directrices en la línea del Catecismo Romano ${ }^{131}$, pero no tuvieron una influencia tan importante en la catequesis posterior cómo el gran catecismo de 1566. El cambio, que se puede notar en el orden catequético, es decir, el paso que dio la catequesis en el siglo XVI del esquema: el credo - la oración - el decálogo - los sacramentos al esquema: el credo - los sacramentos - el decálogo - la oración tuvo sus razones concretas. La principal causa de este cambio fue la Reforma protestane, que en la primera mitad del siglo XVI invadió Europa Occidental. Los protestantes muy pronto se dieron cuenta de que el catecismo, como género literario, constituye un arma muy efectiva en la lucha doctrinal con los católicos ${ }^{132}$. Por eso ya en el año 1520 Lutero empezó a escribir su primer catecismo. Después de nueve años, en Wittenberg en el mismo año salieron dos catecismos de Lutero, el Catecismo Minor y el Catecismo Mayor $^{133}$. El Catecismo Mayor, que era la obra completa, presentaba la doctrina protestante según la secuencia Gebote - Glaube - Gebet - Taufe - Abendmahl, es decir el decálogo - el símbolo de la fe - el padrenuestro - el bautismo - la cena ${ }^{134}$. Esta obra así compilada exponía los mandamientos de la ley en primer lugar para llevar a los catecúmenos al ánimo de la imposibilidad de su cumplimiento y la gravedad de la culpa y disponerlos así a la necesidad absoluta de la fe. Por eso Lutero explicó la fe en segundo lugar y de ella pasó a la oración confiada, el padrenuestro ${ }^{135}$. Por eso también los sacramentos, el bautismo y la cena, los añadió al final de su obra y aunque, en el prólogo de su catecismo escribió que sin ellos

${ }^{131}$ La obra catequética de Erasmo que lleva por título Dilucida et pia explanatio Symboli, quod Apostolorum dicitur, Decalogi praeceptorum, et dominicae orationis, fue editada en el año 1533 en Friburgo. El orden de las cuatro piezas es el mismo que del Catecismo Romano, con la única variante de que los sacramentos se estudian dentro del Símbolo. Cf. J. M. E. Llaurens, P. Rodríguez García, J. A. Gallego, Estudios sobre el Catecismo de la Iglesia Católica, Madrid 1996, p. 14; y también P. Rodríguez, R. Lanzetti, El manuscrito original del Catecismo Romano, pp. 25-31; Federico Nausea redactó su Catecismo dividido en seis libros en 1542 y lo publicó por primera vez en Colonia en 1543. La obra de Nausea, lo mismo que el Catecismo Romano, no está dedicada al pueblo inculto, sino fundamentalmente a los pastores y catequistas, que después lo explicarían a los fieles. El ordo docendi del Catechismus Catholicus guarda una extraordinaria proximidad con el futuro Catecismo de Trento y es el siguiente: el Símbolo-los sacramentos-el decálogo-la oración-las ceremonias y costumbres. Cf. P. Rodríguez, R. Lanzetti, El Catecismo Romano, pp. 147-153.

${ }^{132}$ Basta con mencionar que los dos catecismos de Lutero editados sólo entre años 1525-1560 tenían cien mil ejemplares. Cf. J. Z. Słowiński, Katechizmy katolickie w języku polskim od XVI do XVIII wieku, Lublin 2005, p. 58.

${ }^{133}$ El título Catecismo Mayor fue acogido ya tras la muerte de Lutero. Por primera vez lo aplicó en el año 1541 Juan Spangenberg, el cual editó el Catecismo Mayor en la elaboración particular. Cf. A. Wantuła, Wstęp, w: Wybrane księgi symboliczne Kościoła Ewangelicko-Augsburskiego, Warszawa 1980, p. 23.

${ }^{134}$ Cf. P. Rodríguez, El Catecismo de Carranza y el Catecismo Romano, „Anuario de Historia de la Iglesia", 18 (2009) p. 148.

${ }^{135}$ En el prólogo de su catecismo Lutero escribió: en estas tres piezas ley - fe - oración se comprende todo lo que tenemos en la Sagrada Escritura. Ibídem. 
no se puede ser cristiano, teológicamente los dejó superpuestos, sin contenido $\mathrm{y} \sin$ raices $^{136}$.

Por supuesto, la doctrina protestante así presentada exigía la respuesta por parte de la Iglesia Católica. En el ambiente católico muy pronto se dieron cuenta, que el mejor esquema para exponer la doctrina ortodoxa, sobre todo el tema de la justificación, es el esquema: la fe - los sacramentos - el decálogo - la oración, que el que se había usado hasta ahora: la fe - la oración - el decálogo - los sacramentos. Por eso los autores, que redactaron el Catecismo Romano colocaron a propósito el decálogo detrás de los sacramentos, o mejor es decir los sacramentos entre el símbolo de la fe y el decálogo. En este modo querían presentar que tanto la gracia, como las virtudes, que el Catecismo llama con san Pablo pignus Spiritus Sancti ${ }^{137}$ constituyen al hombre en nueva criatura ${ }^{138}$. La idea es clara: antes de proponerle al cristiano lo que debe hacer, el texto quiere explicarle quién es y cómo es. Porque sólo conociendo la potencia sobrenatural, el cristiano puede abordar, con ánimo confiado y sin temor servil, la plenitud de su existencia, que se le propondrá en el Decálogo ${ }^{139}$. Esta relación entre la gracia y las obras fue entendida ya por los Padres de la Iglesia. El Papa León Magno escribió agnosce, christiane, dignitatem tuam ${ }^{140}$. El mismo Catecismo Romano lo explica así:

Por el bautismo además quedamos incorporados y unidos con Cristo como miembros con su Cabeza. Y así como de la cabeza proviene la energía con que se mueven cada uno de los miembros del cuerpo para el ejercicio de sus propias funciones, del mismo modo de la plenitud de vida de Cristo se difunde sobre los justificados aquella divina virtud y gracia que les hace aptos para todos los deberes de la piedad cristiana ${ }^{141}$.

Y un poco después:

La bondad de Dios nos da las virtudes, de donde nacen las mismas obras ${ }^{142}$.

Podemos decir así: el Decálogo está colocado detrás de los sacramentos porque sin la previa doctrina de los sacramentos, la doctrina sobre los mandamientos

${ }^{136}$ Ibídem.

137 "Nam cum Apostolus ait: Unxit nos Deus, qui et signavit nos, et dedit pignus Spiritus in cordibus nostris, voce illa signavit non obscure characterem descripsit, cuius proprium est aliquid signare et notare." CR-editio critica, p. 174.

${ }^{138}$ Cf. R. Lanzetti, La doctrina sobre la Penitencia en el Catecismo Romano, Pamplona 1979, p. 23.

${ }^{139}$ Cf. J. M. E. Llaurens, P. Rodríguez García, J. A. Gallego, Estudios sobre el Catecismo de la Iglesia Católica, Madrid 1996, p. 16.

${ }^{140}$ Cf. San León Magno, Sermo 21,3 (PL 54, 192).

141 "Iam vero per baptismum etiam Christo capiti tamquam membra copulamur et connectimur. Quemadmodum igitur a capite vis manat, qua singulae corporis partes ad proprias functiones apte exsequendas moventur, ita etiam ex Christi Domini plenitudine in omnes qui iustificantur divina virtus et gratia diffunditur, quae nos ad omnia christianae pietatis officia habiles reddit." CR-editio critica, p. 208.

142 "Id enim ob eam rem non evenit, quod virtutes, a quibus actiones ipsae proficiscuntur." CR-editio critica, pp. 208-209. 
sólo podría llevar a la desesperación luterana ${ }^{143}$. Porque Lutero, saliendo de su experiencia personal, rompió con la tradición catequética y colocó la Ley con sus imposibles exigencias en el primer puesto de su catecismo. El Catecismo Romano al contrario, acentuó que desde la fe y los sacramentos la mirada a los preceptos se llena de confianza y de valor ${ }^{144}$. Por dos veces el Catecismo recordó que el cumplimiento de los mandamientos es posible porque en los sacramentos el cristiano recibe de Dios la gracia y la fuerza. La primera vez, en el caso del Bautismo el Catecismo dice:

confiados en la divina misericordia, debemos esperar firmemente que el cotidiano ejercicio de una santa vida llegue a hacernos fácil y aun agradable todo lo que es puro, justo y santo ${ }^{145}$.

Y la segunda, justo en la introducción al Decálogo se puede leer que no hay razón, pues, para acobardarse, aterrados ante la dificultad de los mandamientos divinos; teniendo siempre a nuestra disposición la ayuda de Dios y los méritos de Cristo, que con su muerte venció y arrojó fuera al príncipe de este mundo, nada será dificil para el que $\mathrm{ama}^{146}$.

El razonamiento del Catecismo viene a ser el siguiente: como Dios por Cristo en el Espíritu Santo me da con sus sacramentos la gracia y todas las virtudes, cuando me manda en el Decálogo la práctica de estas virtudes, podré hacerlo, aunque estoy débil y me cueste, porque tengo en mí una potencialidad divina que supera mis pobres fuerzas humanas. El Catecismo está convencido de que las obras de justicia señaladas en el Decálogo, proceden de las virtudes y de que éstas estan dadas, recuperadas y aumentadas cuando se celebra los sacramentos ${ }^{147}$. En consecuencia, los sacramentos aparecen como el puente que permite transitar al hombre y a la Iglesia desde la fe a las obras de la fe.

${ }^{143}$ Cf. J. M. E. Llaurens, P. Rodríguez García, J. A. Gallego, Estudios sobre el Catecismo, p. 16.

${ }^{144}$ Cf. P. Rodríguez, R. Lanzetti, El manuscrito original del Catecismo Romano, Pamplona 1985, p. 28.

145 "Dei benignitate freti, optima spe niti debeamus fore ut quotidiana recte viviendi exercitatione quaecumque pudica sunt, quaecumque iusta, quaecumque sancta, eadem etiam facilia et iucunda videntur." CR-editio critica, p. 209.

146 "Quia igitur Dei auxilium praesto nobis est, maxime post Christi Domini mortem, per quam princeps huius mundi eiectus est foras, non est quod quisquam rei defficultate deterreatur: nihil enim est amanti difficile." CR-editio critica, p. 401.

${ }^{147}$ Cf. J. M. E. Llaurens, P. Rodríguez García, J. A. Gallego, Estudios sobre el Catecismo de la Iglesia Católica, p. 17. 


\section{BIBLIOGRAFIA}

Alberigo A., Nowe poglądy na Sobór Trydencki, „Concilium”, 1-2 (1965-1966).

Bases críticas para el estudio teológico del Catecismo del Concilio de Trento 1566, Pamplona 1982.

Bedouelle G., Das Entstehen des Catechismus, „Communio”, 12 (1983) n. 1.

Catechismus Romanus, Libreria Editrice Vaticana / Ed. Universidad de Navarra, Città del Vaticano 1989.

Etchegaray-Cruz A., Storia della catechesi, Roma 1984.

Gallego J. A., Estudios sobre el Catecismo de la Iglesia Católica, Madrid 1996.

Illanes J. L., Saranyana J. I., Historia de la Teología, Madrid 1996.

Jedin H., Geschichte des Konzils von Trient, Bd. 4: Dritte Tagunsperiode und Abschluss, Freiburg 1975.

Lanzetti R., La doctrina sobre la Penitencia en el Catecismo Romano, Pamplona 1979.

Llaurens J. M. E., Rodríguez García P., Gallego J. A., Estudios sobre el Catecismo de la Iglesia Católica, Madrid 1996.

Lluch-Baixauli M., Formación y evolución del tratado escolástico sobre el decálogo (1115-1230), Louvain 1997.

Mielczarek J., Komunia pod dwiema postaciami w ustawodawstwie Kościoła Zachodniego, Lublin 1983.

Ortiz J., El sacramento del matrimonio en la exposición del Catecismo Romano, Pamplona 1981.

Paschini P., Cinquecento romano e riforma cattolica, Roma 1958.

Popielec M., Katechizm kaliski i jego znaczenie dla polskich edycji Katechizmu Rzymskiego, Lublin 1970.

Popielec M., Katechizm kaliski i jego znaczenie dla polskich edycji Katechizmu Rzymskiego, Lublin 1970.

Renouard A. A., Annales de 1' imprimerie des Alde, ou histoire des trois Manuce et de leurs éditions, Paris 1834.

Resines L., La catequesis en España. Historia y textos, Madrid 1997.

Rodríguez P., El Catecismo de Carranza y el Catecismo Romano, „Anuario de Historia de la Iglesia", 18 (2009).

Rodríguez P., El Catecismo de la Iglesia Católica: interpretación histórico-teológica. Lección inaugural del curso académico 1994-1995 en la Universidad de Navarra, Pamplona 1994.

Rodríguez P., Lanzetti R., El Catecismo Romano: fuentes e historia del texto y de la redacción.

Rodríguez P., Lanzetti R., El manuscrito original del Catecismo Romano. Descripción del material y los trabajos al servicio de la edición crítica del Catecismo del Concilio de Trento. Pamplona 1985.

Schneider B., Hoffaeus Paul, Lexikon für Theologie und Kirche, vol. 5, Freiburg 1960.

Słowiński J. Z., Katechizmy katolickie w języku polskim od XVI do XVIII wieku, Lublin 2005.

Szorc A., Korespondencja Stanisława Hozjusza kardynała i biskupa warmińskiego, vol. 5, Anno 1564, „Studia Warmińskie”, 13 (1976).

Villoslada R., Pedro Guerrero, representante de la reforma española en Il Concilio di Trento e la riforma tridentina. Atti del Convegno Storico Internazionale, Vicenza 1965.

Wantuła A., Wstęp, w: Wybrane księgi symboliczne Kościoła Ewangelicko-Augsburskiego, Warszawa 1980.

Wolny J., Z dziejów katechezy, w: Dzieje teologii katolickiej w Polsce, red. M. Rechowicz, vol. 1, Lublin 1974. 


\title{
THE CREATION AND STRUCTURE OF THE ROMAN CATECHISM
}

\begin{abstract}
Summary
The article presents a little-known story of the origin and structure of the first official catechism of the Catholic Church, the Roman Catechism. Although the idea of creating a single, universal catechism for the whole Church already existed in the 15th century, its implementation began only after Luther's breach with the Roman Catholic Church and the division of Christianity. Work on the new catechism began at the Council of Trent on 5 April 1546 and was completed after its closure, 23 September 1566. In the meantime, the project underwent many changes. Due to the emergence of Protestantism, the very nature of the work as well as its application were strongly disputed. Some theologians and representatives of the secular authority opted for the creation of a polemical catechism, but the majority supported a positive interpretation of the Catholic doctrine.

In addition to the history of the text, the article focused on the internal structure of the work. From the patristic times onwards, religious education revolved around four basic elements: the profession of faith, the Ten Commandments, the sacraments and prayer. Over time these elements became part of all catechisms, including the Roman Catechism. However, they did not always follow the same pattern. While most of the Catholic catechisms were written in accordance with the following pattern: the profession of faith - prayer the Ten Commandments - the sacraments, the Roman Catechism presented a new order: the profession of faith - the sacraments - the Ten Commandments - prayer. According to the research conducted in the article, this pattern was probably used deliberately, because it was more suitable for the Catholic doctrine of justification.
\end{abstract}

Keywords: the Roman Catechism, the Council of Trent, the Reformation

Translated by Aneta Kiper

\section{POWSTANIE I STRUKTURA KATECHIZMU RZYMSKIEGO}

\section{Streszczenie}

Artykuł przybliża mało znaną historię powstania i strukturę pierwszego oficjalnego katechizmu Kościoła Katolickiego, tak zwanego Katechizmu Rzymskiego. Prace nad nowym katechizmem rozpoczęto na Soborze Trydenckim, 5 kwietnia 1546 roku, a ukończono już po jego zamknięciu, 23 września 1566 roku. W związku z pojawieniem się protestantyzmu, najwięcej dyskusji wzbudzał sam charakter dzieła, a także jego zastosowanie. Część teologów i przedstawicieli władzy świeckiej optowała za stworzeniem katechizmu typowo polemicznego, jednak większość była zwolennikami pozytywnej wykładni doktryny katolickiej.

W artykule, oprócz historii powstania tekstu, analizie poddano również wewnętrzną strukturę dzieła. Podczas gdy większość katechizmów katolickich była napisana według schematu: wyznanie wiary - modlitwa - dekalog - sakramenty, Katechizm Rzymski prezentował nowy porządek: wyznanie wiary - sakramenty - dekalog - modlitwa.

Słowa kluczowe: Katechizm Rzymski, Sobór Trydencki, reformacja 